Abstracted/indexed in Academic Search Complete, Asia Journals Online, Bangladesh Journals Online, Biological Abstracts, BIOSIS Previews, CAB Abstracts, Current Abstracts, Directory of Open Access Journals, EMBASE/Excerpta Medica, Google Scholar, HINARI (WHO), International Pharmaceutical Abstracts, Open J-gate, Science Citation Index Expanded, SCOPUS and Social Sciences Citation Index;

ISSN: $1991-0088$

\title{
Prescribing pattern of non-steroidal anti-inflammatory drugs at outpatient departments of teaching hospitals
}

\author{
Md. Shamsur Rahman', Zinnat Ara Begum' and Md. Khoshroz Samad² \\ ${ }^{1}$ Department of Pharmacology and Therapeutics, Dhaka Medical College, Dhaka 1000; ${ }^{2} 81$ Field Ambulance, \\ Mymensingh Cantonment, Mymensingh 2200, Bangladesh.
}

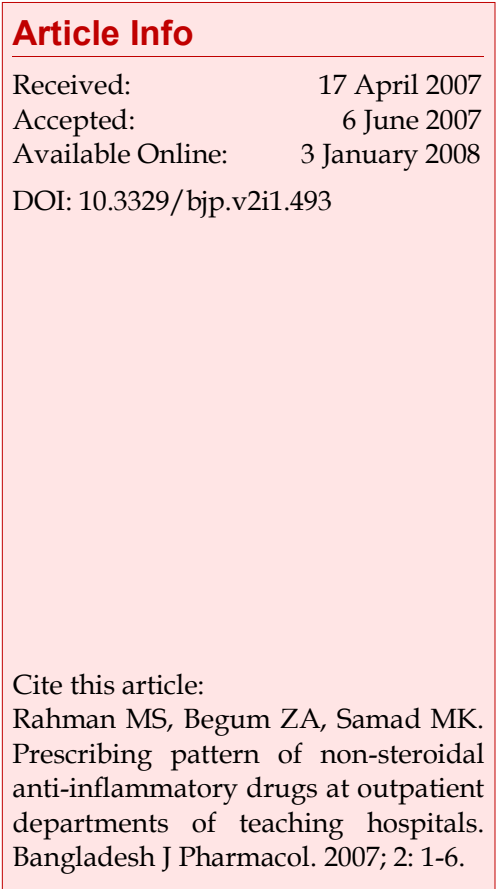

\begin{abstract}
The prescribing pattern of non-steroidal anti-inflammatory drugs (NSAIDs) in prescriptions prescribed by the qualified medical personnel in the outpatient departments of three selected teaching hospitals in Dhaka city were studied. A total of 600 prescriptions containing NSAIDs were collected. The clinical conditions for which NSAIDs prescribed were identical in all the three hospitals, although there were wide variations in the prescribing pattern with respect to pharmacological sub-classes of NSAIDs. Analgesics with no or minimal anti-inflammatory effects were the most commonly prescribed NSAIDs in the Medical Outpatient Departments of Dhaka Medical College Hospital (DMCH) and Bangabandhu Sheikh Mujib Medical University Hospital (BSMMUH) whereas analgesics with potent anti-inflammatory effects were the most commonly prescribed NSAIDs in a private teaching hospital $(\mathrm{PH})$. Moreover, the prescribers in $\mathrm{PH}$ had to prescribe additional drugs than those of the prescribers of DMCH and BSMMUH to counter the adverse effects of NSAIDs. Proton pump inhibitors were mainly used in Medical Outpatient Departments whereas $\mathrm{H}_{2}$ blockers were in Surgical Outpatient Departments. Consequently, the cost of prescribed NSAIDs per prescription and ultimately the cost of total drugs per prescription became more expensive in $\mathrm{PH}$ compared to DMCH and BSMMUH. In conclusion, it may be said that the overall prescribing pattern of NSAIDs among three hospitals is rational.
\end{abstract}

\section{Introduction}

The total number of registered physicians in Bangladesh is 32,498 , thus making one physician for every 4,000 people (WHO, 2000). In the absence of enough qualified doctors, drugs are often prescribed by unqualified health workers and people can get any drug from any drug store without a prescription. Each day new drugs with higher cost are coming into market in a large scale. Family/individuals have to spend big amount of money for purchasing drugs. For example,
Bangladesh spent Tk. 5,500 crores in health only in the year 1996-97, out of which total spending on drugs was Tk. 2,700 crores (49\%). But it was found that the family/ individuals had to spend Tk. 2,500 crores which is about $90.7 \%$ of total spending on drugs. Government and other sources spent only Tk. 250 crores for drugs (Bangladesh National Health Accounts, 1996-97).

Irrational prescribing has further complicated the drug use problem. Numerous studies, both from developed and developing countries, describe it as a pattern 
consisting of polypharmacy, use of drugs that are not related to the diagnosis, or unnecessarily expensive, irrational use of antibiotics, and irrational selfmedication, with many drugs taken in insufficient quantities (Hogerzeil, 1988). The global trend from public to private sector spending, particularly in developing countries including Bangladesh results in an even larger proportion of drugs being purchased without any prescription at all. Rational prescribing is therefore one important aspect of rational use of drugs.

One of the most widely used and abused drugs all over the world are pain-killers, pain is an unpleasant sensory and emotional experience associated with actual or potential tissue damage, or described in terms of such damage (Bennett and Brown, 2004). Fever and pain are usually the early symptoms of most of the inflammatory diseases. From the very beginning of human civilization, man has been trying to find the way of controlling these symptoms and maintaining good health. The introduction of non-steroidal antiinflammatory drugs (NSAIDs) was a landmark event and soon these drugs become the most widely used medication not only for the relief of pain and fever but also for their anti-inflammatory effect.

The NSAIDs are available as over-the-counter (OTC) products and are widely misused and abused. Moreover, their uses are not always without severe adverse effects. Like most drugs they are double-edged swords. So, sporadic consumption of NSAIDs may subside the symptoms for time being but the actual pathology may sometimes not only be hindered but also be aggravated, complicated and even turn to fatality in some cases (Chowdhury, 1991). However, we do not have adequate information regarding the prescribing pattern of NSAIDs by the medical prescribers particularly with respect to their recommended uses to counter ailments occurring in the community.

The aim of this study is to obtain information regarding the prescribing pattern of NSAIDs by the medical prescribers in the outpatient departments of some selected teaching hospitals in Dhaka city. The outpatient departments have been chosen because both rural and urban population of different classes and socio-economic background daily come to these outpatient departments from various parts of Bangladesh to take treatment of their common diseases. The prescribing pattern of the outpatient departments of tertiary level hospitals are often copied by community practitioners and health workers. Needless to say that these unqualified community practitioners and health workers tremendously influence the drug utilization pattern in the community and often contribute to misuse and over utilization of drugs.

\section{Materials and Methods}

This prospective cross sectional (descriptive) study was carried out in medical and surgical outpatient departments of three selected hospitals [Dhaka Medical College Hospital (DMCH), Bangabandhu Sheikh Mujib Medical University Hospital (BSMMUH), and a private teaching hospital (PH) in Dhaka city]. The study was designed to obtain information regarding the prescribing pattern of NSAIDs by the medical prescribers. Duration of study period was one year (July 2003 to June 2004).

\section{Study design}

The prescriptions given by the medical officers and specialist doctors were collected from patients attending the outpatient departments. Of them the prescription which did not contain NSAIDs were excluded. A total of 600 prescriptions containing NSAIDs (100 from each outpatient department of three hospitals) were collected, photocopied and later analyzed for information like- clinical indications for which NSAIDs were prescribed, pharmacological subclasses of NSAIDs prescribed, average number of drugs per prescription, drugs prescribed to counter the adverse effects of NSAIDs, the percentages of drugs prescribed in generic names and average costs of drugs and of NSAIDs per prescription.

\section{Analysis of data}

Data were analyzed by using percentage. As it was a descriptive study statistical analysis was not done.

\section{Results}

The commonest clinical indications for prescribing NSAIDs in the medical outpatient departments of three hospitals were backache followed by fever, infective condition, musculoskeletal pain, and headache (Table I). On the other hand, the commonest clinical indications for prescribing NSAIDs in the surgical outpatient departments were traumatic injury followed by backache, fever, musculoskeletal pain and headache. The clinical indications for prescribing NSAIDs were almost identical among the three hospitals. However, it was interesting that $\mathrm{DMCH}$ in either of medical or surgical outpatient department had no prescription with NSAIDs for clinical complaints of musculoskeletal pain.

Analgesics with no or minimal anti-inflammatory effects were the most commonly prescribed NSAIDs in the medical outpatient departments of DMCH (86\%) and BSMMUH (64\%), followed by selective COX-2 inhibitors and analgesics with potent anti-inflammatory effects (Table II). However, in PH, the most commonly 


\begin{tabular}{|c|c|c|c|c|c|c|}
\hline \multicolumn{7}{|c|}{ Table I } \\
\hline \multicolumn{7}{|c|}{ Clinical indications for which NSAIDs were prescribed } \\
\hline \multirow[t]{2}{*}{ Clinical indications } & \multicolumn{3}{|c|}{ Medical outpatient department } & \multicolumn{3}{|c|}{ Surgical outpatient department } \\
\hline & $\begin{array}{c}\text { DMCH } \\
(\mathrm{n}=100) \%\end{array}$ & $\begin{array}{l}\text { BSMMUH } \\
(\mathrm{n}=100) \%\end{array}$ & $\begin{array}{c}\text { PH } \\
(\mathrm{n}=100) \%\end{array}$ & $\begin{array}{c}\text { DMCH } \\
(\mathrm{n}=100) \%\end{array}$ & $\begin{array}{l}\text { BSMMUH } \\
(\mathrm{n}=100) \%\end{array}$ & $\begin{array}{c}\text { PH } \\
(\mathrm{n}=100) \%\end{array}$ \\
\hline Backache & 50 & 40 & 53 & 40 & 26 & 28 \\
\hline Traumatic injury & 0 & 0 & 0 & 45 & 37 & 34 \\
\hline Fever & 25 & 30 & 20 & 11 & 17 & 19 \\
\hline Infective condition & 15 & 12 & 8 & 0 & 0 & 0 \\
\hline Musculoskeletal pain & 0 & 8 & 10 & 0 & 12 & 10 \\
\hline Headache & 7 & 6 & 6 & 2 & 0 & 0 \\
\hline Others & 3 & 4 & 3 & 2 & 8 & 9 \\
\hline
\end{tabular}

Table II

\section{Pharmacological sub-classes of NSAIDs prescribed}

\begin{tabular}{|c|c|c|c|c|c|c|}
\hline \multirow[t]{2}{*}{ Pharmacological sub-classes of NSAIDs } & \multicolumn{3}{|c|}{ Medical outpatient department } & \multicolumn{3}{|c|}{ Surgical outpatient department } \\
\hline & $\begin{array}{l}\text { DMCH } \\
(\mathrm{n}=100)\end{array}$ & $\begin{array}{l}\text { BSMMUH } \\
(\mathrm{n}=100)\end{array}$ & $\begin{array}{c}\text { PH } \\
(\mathrm{n}=100)\end{array}$ & $\begin{array}{l}\text { DMCH } \\
(\mathrm{n}=100)\end{array}$ & $\begin{array}{l}\text { BSMMUH } \\
(\mathrm{n}=100)\end{array}$ & $\begin{array}{c}\text { PH } \\
(n=100)\end{array}$ \\
\hline $\begin{array}{l}\text { Analgesic with no or minimal anti- } \\
\text { inflammatory effect (eg. paracetamol, ibu- } \\
\text { profen, mefenamic acid) }\end{array}$ & 86 & 64 & 30 & 7 & 12 & 0 \\
\hline $\begin{array}{l}\text { Analgesic with anti-inflammatory effect (eg. } \\
\text { diclofenac sodium, aceclofenac, indomethacin, } \\
\text { naproxen, ketorolac) }\end{array}$ & 6 & 13 & 58 & 61 & 78 & 93 \\
\hline $\begin{array}{l}\text { Selective COX-2 inhibitor (eg. celecoxib, } \\
\text { rofecoxib, valdecoxib) }\end{array}$ & 8 & 23 & 12 & 32 & 10 & 7 \\
\hline
\end{tabular}

prescribed NSAIDs were analgesics with potent antiinflammatory effects (58\%) followed by analgesic with no or minimal anti-inflammatory effects $(30 \%)$ and selective COX-2 inhibitors (12\%). In the surgical outpatient departments, the most commonly prescribed NSAIDs were analgesics with potent anti-inflammatory effects $(61 \%$ in $\mathrm{DMCH}, 78 \%$ in BSMMUH and $93 \%$ in $\mathrm{PH})$, followed by selective COX-2 inhibitors (32\% in $\mathrm{DMCH}, 10 \%$ in BSMMUH and $7 \%$ in $\mathrm{PH})$ and analgesics with no or minimal anti-inflammatory effects (7\% in DMCH, 12\% in BSMMUH). Of the total 600 prescriptions containing NSAIDs, the average number of drugs per prescription in the medical and surgical outpatient departments was ranging from 2.5 to 3.3. The average number of drugs per prescription was slightly higher in $\mathrm{PH}$ compared to $\mathrm{DMCH}$ and BSMMUH.

The prescriptions containing additional drugs to prevent the adverse effects of NSAIDs in the medical outpatient departments were $30,50,75 \%$ and the surgical outpatient departments were 85,80 and $90 \%$ in $\mathrm{DMCH}, \mathrm{BSMMUH}$ and $\mathrm{PH}$ respectively. Of them, $\mathrm{H}_{2}$ blockers prescribed in the medical outpatient departments were $40 \%$ (out of $30 \%$ in $\mathrm{DMCH}$ ), $28 \%$ (out of $50 \%$ in BSMMUH), $13.3 \%$ (out of $75 \%$ in $\mathrm{PH}$ ) and in the surgical departments were $61.2 \%$ (out of $85 \%$ in $\mathrm{DMCH}$ ), $77.5 \%$ (out of $80 \%$ in BSMMUH), $91.1 \%$ (out of $90 \%$ in $\mathrm{PH}$ ). On the other hand, proton pump inhibitors prescribed in the medical outpatient departments were $60 \%$ (out of $30 \%$ in $\mathrm{DMCH}$ ), $72 \%$ (out of $50 \%$ in BSMMUH), $86.7 \%$ (out of $75 \%$ in $\mathrm{PH}$ ) and the surgical departments were $38.8 \%$ (out of $85 \%$ in DMCH), $22.5 \%$ (out of $80 \%$ in BSMMUH), and $8.9 \%$ (out of $90 \%$ in $\mathrm{PH}$; Table III). Proton pump inhibitors were the drugs used maximally to prevent adverse effects in medical outpatient departments of all three teaching hospitals, while $\mathrm{H}_{2}$-blockers were the drugs used maximally in surgical outpatient departments of all three hospitals.

The percentages of drugs prescribed in generic names in the medical outpatient departments were 14.2, 15.5, 6.2 and in the surgical outpatient departments were 12.1, 13.2, and 3.7 respectively of $\mathrm{DMCH}, \mathrm{BSMMUH}$, and $\mathrm{PH}$. The generic prescribing was higher in both medical and surgical outpatient departments of $\mathrm{DMCH}$ 
Table III

Drugs prescribed to counter the adverse effects of NSAIDs

\begin{tabular}{|c|c|c|c|c|c|c|}
\hline \multirow{2}{*}{$\begin{array}{l}\text { Additional } \\
\text { drugs }\end{array}$} & \multicolumn{2}{|c|}{$\mathrm{DMCH}$} & \multicolumn{2}{|c|}{ BSMMUH } & \multicolumn{2}{|c|}{$\mathrm{PH}$} \\
\hline & $\begin{array}{l}\text { Medical out- } \\
\text { patient depart- } \\
\text { ment }(n=100)\end{array}$ & $\begin{array}{l}\text { Surgical out- } \\
\text { patient depart- } \\
\text { ment }(\mathrm{n}=100)\end{array}$ & $\begin{array}{l}\text { Medical out- } \\
\text { patient depart- } \\
\text { ment }(\mathrm{n}=100)\end{array}$ & $\begin{array}{l}\text { Surgical out- } \\
\text { patient depart- } \\
\text { ment }(\mathrm{n}=100)\end{array}$ & $\begin{array}{l}\text { Medical out- } \\
\text { patient depart- } \\
\text { ment }(\mathrm{n}=100)\end{array}$ & $\begin{array}{l}\text { Surgical out- } \\
\text { patient depart- } \\
\text { ment }(\mathrm{n}=100)\end{array}$ \\
\hline $\begin{array}{l}\text { Drugs pre- } \\
\text { scribed to } \\
\text { counter the } \\
\text { adverse } \\
\text { effects of } \\
\text { NSAIDs }\end{array}$ & 30 & 85 & 50 & 80 & 75 & 90 \\
\hline $\mathrm{H}_{2}$ blockers & 40 & 61.2 & 28 & 77.5 & 13.3 & 91.1 \\
\hline $\begin{array}{l}\text { Proton } \\
\text { pump in- } \\
\text { hibitors }\end{array}$ & 60 & 38.8 & 72 & 22.5 & 86.7 & 8.9 \\
\hline
\end{tabular}

Table IV

\begin{tabular}{|c|c|c|}
\hline \multicolumn{3}{|c|}{$\begin{array}{c}\text { The percentage of generic prescribing in the outpa- } \\
\text { tient departments }\end{array}$} \\
\hline \multirow[t]{2}{*}{ Name of hospital } & \multicolumn{2}{|c|}{ Percentages of drugs in generic form } \\
\hline & $\begin{array}{l}\text { Medical outpa- } \\
\text { tient department } \\
\quad(\mathrm{n}=300)\end{array}$ & $\begin{array}{l}\text { Surgical outpa- } \\
\text { tient department } \\
\quad(\mathrm{n}=300)\end{array}$ \\
\hline $\mathrm{DMCH}$ & 14.2 & 12.1 \\
\hline BSMMUH & 15.5 & 13.2 \\
\hline PH & 6.2 & 3.7 \\
\hline
\end{tabular}

and BSMMUH as compared to PH (Table IV).

Average cost of prescribed drugs per prescription in the medical outpatient departments were Tk. 149.4, 166.7, 339.6 and the surgical outpatient departments were 157.2, 177.7, 230.6 respectively of DMCH, BSMMUH and $\mathrm{PH}$ (Table V). The average cost of drugs per prescription was higher in both the outpatient departments of $\mathrm{PH}$ as compared to $\mathrm{DMCH}$ and BSMMUH. Average cost of prescribed NSAIDs per prescription in the medical outpatient departments were Tk. 24.8, 30.5, 60.4 and the surgical outpatient departments were Tk. $57.4,66.9,80.9$ respectively of DMCH, BSMMUH and PH (Table V). The average cost of prescribed NSAIDs per prescription was higher in both the outpatient departments of $\mathrm{PH}$ as compared to $\mathrm{DMCH}$ and BSMMUH.

\section{Discussion}

The main objective of this study was to assess the prescribing pattern of NSAIDs at the tertiary level hospitals (one of them was government, one was autonomous and the other was private). The tertiary level hospitals had been chosen because the prescribing pattern of the outpatient departments of tertiary level hospitals are often copied by community practitioners and health workers.

The commonest clinical indications for prescribing NSAIDs in the medical and surgical outpatient departments were backache and traumatic injury in $\mathrm{DMCH}$, BSMMUH and PH respectively. The clinical indications for prescribing NSAIDs were almost identical among the three hospitals.

Although the clinical conditions for which NSAIDs prescribed were identical in all three hospitals, there was substantial variation in the prescribing pattern with respect to pharmacological sub-classes of NSAIDs in the medical outpatient departments of $\mathrm{DMCH}$, BSMMUH and PH on the other hand. Analgesics with no or minimal anti-inflammatory effects were the most commonly prescribed NSAIDs in the medical outpatient departments of DMCH and BSMMUH whereas analgesics with potent anti-inflammatory effects were the most commonly prescribed NSAIDs in the same outpatient department of PH. Probably, the reason behind it was that educated and higher income group of patients mostly attended the outpatient department of $\mathrm{PH}$ and they were familiar with the name of analgesics having no or minimal antiinflammatory effects like paracetamol, ibuprofen, etc. On the contrary, less educated and lower income group of patients generally attended the outpatient departments of DMCH and BSMMUH and they received prescriptions from the medical outpatient departments containing analgesics with no or minimal anti-inflammatory effects as they were very cheap and mostly available in those hospitals. These analgesics with no or minimal anti-inflammatory effects have lower incidence of adverse effects particularly in the gastrointestinal tract, especially with paracetamol and 


\begin{tabular}{|c|c|c|c|c|}
\hline \multicolumn{5}{|c|}{ Table V } \\
\hline \multicolumn{5}{|c|}{ The average cost of drugs per prescription } \\
\hline \multirow[t]{2}{*}{$\begin{array}{l}\text { Name of } \\
\text { hospital }\end{array}$} & \multicolumn{2}{|c|}{$\begin{array}{l}\text { Medical outpatient department } \\
(\mathrm{n}=300)\end{array}$} & \multicolumn{2}{|c|}{$\begin{array}{l}\text { Surgical outpatient department } \\
\qquad(\mathrm{n}=300)\end{array}$} \\
\hline & $\begin{array}{l}\text { Average cost of drugs } \\
\text { per prescription (Tk) }\end{array}$ & $\begin{array}{l}\text { Average cost of NSAIDs } \\
\text { per prescription (Tk) }\end{array}$ & $\begin{array}{l}\text { Average cost of drugs } \\
\text { per prescription (Tk) }\end{array}$ & $\begin{array}{l}\text { Average cost of NSAIDs } \\
\text { per prescription (Tk) }\end{array}$ \\
\hline $\mathrm{DMCH}$ & 149.4 & 24.8 & 157.2 & 57.4 \\
\hline BSMMUH & 166.7 & 30.5 & 177.7 & 66.9 \\
\hline $\mathrm{PH}$ & 339.6 & 60.4 & 230.6 & 80.9 \\
\hline
\end{tabular}

ibuprofen at low dose (Bennett and Brown, 2004). Moreover, the prescribers in the medical outpatient department of $\mathrm{PH}$ had to prescribe additional drugs than those of the prescribers of DMCH and BSMMUH to counter the adverse effects of NSAIDs. Consequently, the cost of prescribed NSAIDs per prescription and ultimately the cost of total drugs per prescription became more expensive in the medical outpatient department of $\mathrm{PH}$ compared to DMCH and BSMMUH. In South Africa (Truter, 1997) investigators observed that analgesic agents represented $12.3 \%$ of total number and $14.2 \%$ of total cost of products prescribed.

However, in the surgical outpatient departments, the most commonly prescribed NSAIDs were analgesics with potent anti-inflammatory effects showing no wide variation in the prescribing pattern with respect to pharmacological sub-classes of NSAIDs among the surgical out-patients departments of three teaching hospitals.

The purpose to find out the average number of drugs per prescription is to measure the degree of polypharmacy. Because over prescribing or polypharmacy causes high level of irrational drug consumption and badly affects the rational prescribing which increases the risk of adverse reaction of drugs including drug interaction (Anwar, 1994). The average number of drugs per prescription was slightly higher in $\mathrm{PH}$ compared to DMCH and BSMMUH. However, the present obtained data regarding the average number of drugs per-prescription was comparable with that observed by others (Rahman et al., 1998). They found the mean number of drugs per prescription was 3.1. Average number of drugs per prescription observed in Tanzania was 2.4 (WHO Report, 1995). So, the present finding did not show any polypharmacy and this was an example of rational prescribing.

The percentages of drugs prescribed in generic names were determined because generic prescription has got special importance for rational use of drug as regards to cost, safety and efficacy by permitting the identification of the products by its scientific names (Ara and Chowdhury, 2001). Moreover, generic drugs by permitting the identification of the products by its scientific names make it easier for the prescribers, dispenser and users to choose between many alternative competing in terms of quality, price or convenience. It was found that percentages of generic prescribing were more in $\mathrm{DMCH}$ and BSMMUH compared to $\mathrm{PH}$. Though the practice of generic name was found to be very low previously in a teaching hospital (Ali and Chowdhury, 1993). As NSAIDs are sold in the market in trade name, therefore prescribers do not have much option in this regard. Pressure from pharmaceutical companies may be one of the reasons for writing trade name. It was observed that in Cyprus, $20 \%$ of drugs were prescribed as generic (WHO Report, 1993).

However, it may be mentioned that overall prescribing pattern of NSAIDs among three hospitals is rational, although there are scopes for improvement by introducing appropriate educational intervention for rational prescribing. This may be considered as an effort to improve the quality of health care.

\section{Acknowledgement}

We would like to acknowledge the help of Prof. A.K.M. Nurul Anwar of Ibrahim Medical College, Dhaka for constructive criticism of the manuscript.

\section{References}

Ali L, Chowdhury SAR. Study of drug utilization pattern at a teaching hospital. Bangladesh J Physiol Pharmacol. 1993; 9: 27-28.

Anwar, AKMN. Editorial: Role of medical colleges in promoting rational use of drugs. Bangladesh J Physiol Pharmacol. 1994; 10: 1-2.

Ara F, Chowdhury SAR. Pattern of drug use for under-five children in acute respiratory infections in three selected teaching hospitals in Dhaka city. Bangladesh J Physiol Pharmacol 2001; 17: 33-36.

Bangladesh National Health Accounts. Health Economic Units, 
Ministry of Health and Family Welfare, Bangladesh. 19961997.

Bennett PN, Brown MJ. Inflammation, arthritis and nonsteroidal anti-inflammatory drugs. In: Clinical pharmacology. 9th ed, New York, Churchill Living-stone, 2004, pp 279-98.

Bennett PN, Brown MJ. Pain and analgesics. In: Clinical pharmacology. New York, Churchill Livingstone, 9th edn, 2004, pp 319-43.

Chowdhury SAR. Prescribing a rational drug. Bangladesh J Physiol Pharmacol. 1991; 17: 1.

Hogerzeil HV. Promoting rational prescribing: An international perspective. In: International experience in rational use of drugs. Chowdhury RR. Bangkok, Coll Public Health, 1988, pp 1-2.
Rahman MS, Begum M, Khan IA. A baseline survey on use of drugs at private practitioner level in Bangladesh. Bangladesh J Physiol Pharmacol. 1998; 14: 47-50.

Truter I. Patterns of analgesic prescribing in a South African primary care setting. J Clin Pharm Ther. 1997; 22: 33-7.

WHO Report. Cyprus holds second workshop on rational drug use. Essential Drugs Monitor, 1993; 16: 6.

WHO Report. Tanzania: Workshop promotes essential drug concept. Essential Drugs Monitor, 1995; 20: 15.

WHO. Health situation in the South East Asia region, 19982000.

WHO/DAP. How to investigate drug use in health facilities. 1993, pp 25-31. 